\title{
The Analysis of The Push Pull Motivation Factor and The Expectation of International Tourist in Ramayana Ballet Prambanan Yogyakarta
}

\author{
Momentya Irsha \\ Universitas Gadjah Mada, Indonesia \\ Email: momentya95@gmail.com
}

\begin{abstract}
Cultural attraction in a country or region is an attraction that is demanded by international tourist, because tourists obviously want to know the culture of that country, such as by watch the dance. Ramayana Ballet Prambanan is a dance presents Javanese culture, both Central Java and Yogyakarta Special Region. This performance tells about Ramayana that is illustrated on the relief of Prambanan Temple. This study analyzes the push and pull factors of motivation, and expectation. Respondents of this study is international tourists.

The writer adapted the push and pull factor developed by Crompton (1979), and suited by the condition of Ramayana Ballet Prambanan. The method used by the writer is interview with 65 respondents. While, expectation theory is adapted from Oliver (1980) through questionnaire method with 100 respondents. Furthermore, for the analytical purpose of this research, the data is analyzed by using SPSS 20 with descriptive analysis. The result showed that the push factor motivation of international tourist is new experience, and the pull factor is the attractiveness of Javanese culture. In addition, the biggest expectation of international tourist is cleanliness.
\end{abstract}

Keywords: tourist motivation, push factor, pull factor, tourist expectation, performance art, Ramayana Ballet Prambanan

\section{Background}

Cultural tourism includes visiting to historical buildings and sites, museums, art galleries, and also viewing contemporary paintings or sculpture, or attending the performing arts (Richards, 1994, as cited by Hughes 1996: 707). One of famous cultural attractions in Yogyakarta is Ramayana Ballet which is located in Prambanan. The Ramayana Ballet performance is a colossal classic dance which involves 200 artists, dancers, and Gamelan musicians. It mixes Javanese arts, such as dance, drama, and music in a stage to perform Ramayana story. This ballet performance is managed by PT Taman Wisata Candi Borobudur, Prambanan, dan Ratu Boko (PT TWC) since 1961. The issue that is interesting is the increasing number of visitors of international tourists. Table 1.1 shows the increasing number of international tourists of Ramayana Ballet Prambanan in 2016.

It could be many reasons why international tourists increased. Unfortunately, there are limited numbers of research in finding out the reason of phenomena. Moreover, it is very important to analyze some factors that influence the increase of international tourists. Those factors can be formed because of the push factors as well as the pull factors. In addition, the understanding of expectation behind the interest of international tourists to see Ramayana Ballet performance can be used as the base of strategic formulation to improve the Ramayana Ballet performance and management. Compared with some previous studies that have 
similar the focus, such as, Endar Sri Wijayanti (2015) in her thesis Open Air Theatre of Ramayana Ballet Prambanan: The Stage, Seat Arrangement and Its Influence Towards the Audience that mostly discussed the technical of performance art, The Role of Stage Manager in Ramayana Ballet Prambanan Management that is conducted by Nataya Belinda (2014) presented the management of performance, and study from Sholihin Dunamar L. (2014) in his paper entitled Strategy of Ramayana Ballet Prambanan Yogyakarta Product Development that focused on the product development strategy, while this study investigates the psychological factor of understanding the reason behind international tourists who come to the ballet and their expectation towards the performance as well. By understanding tourist's motivation and expectation, academic empirical guidance for developing the ballet will be presented.

In this study, the author limits the observation in Ramayana Ballet Prambanan by observing the Open Air and Trimurti theatre in January to February 2017 to identify the push and pull motivation factors, and expectations of international tourists. This study can be used as a reference in planning and formulating strategy to run a performance art.

Table 1. Number of International Tourists Visiting Ramayana Ballet Prambanan in 2012-2016

\begin{tabular}{|c|c|c|}
\hline No & Year & Amount \\
\hline 1 & 2012 & 16.890 \\
\hline 2 & 2013 & 17.301 \\
\hline 3 & 2014 & 20.482 \\
\hline 4 & 2015 & 25.069 \\
\hline 5 & 2016 & 27.472 \\
\hline
\end{tabular}

(Source: Operational Division of Ramayana Ballet Prambanan, 2016)

\section{Teoritical Framework}

Motivation is that which gives people a desire to behave in certain ways or the reason people do things. Simply, push motivation factors are those that force the individual to move and come to a destination, while push motivation factors are those factors in the destination that attract the individual or group to leave their home. Hill (1965: 12) states the motive of many vacation makers is in a response to psychological depletion and is an opportunity to allow the tourist to replenish and restore, if the traveler finds what they want they will come back enriched, regenerated, and recharged. While Dann (1977:184) defines that by going away on vacation an individual is able to escape the suppressing feeling of isolation in everyday life and obtain social interaction by getting away from the norms of everyday living.

The expectation is the feeling that something is about to happen. In other words, an expectation of one of the other people is different. Expectation can be interpreted as the imagination of people of what will they get, or do. Lee (2011:1115) explains that tourists have high expectations so that they are more willing to search for tour information, acquire knowledge regarding the destination culture, and other information. The relationship between motivation and expectation is that motivation can be conceptualized as the product of expectancy and valence (Hsu, et al., 2010:282). Tourism motivation can be divided into push and pull factors (Yuan \& McDonald, 1990:42). Dann (1997:184) explains that push factors as the motive that drives a tourist away from home, while pull factors as the motives in which drive a tourist towards a destination. Push and pull motivation factors have been widely accepted to explain tourist behaviour and travel motivations (Crompton, 1979; Uysal \& Hagen, 1993; as cited in Chan \& Baum, 2007:359).

With more complexity the push factors encouraging a person to travel are the sociopsychological needs of a person (Yoon \& Uysal, 2005: 45) and the pull factors are the motivations arousing a person to visit a particular destination (Buhalis, 2003; Flucker \& Turner; as cited in Chan \& Baum, 2007: 349). Based on the push and pull approach, people are pushed by internal desires, such as personal escape, psychological or physical health, thrill and adventure, and social interactions (Baloglu and Uysal, 1996). Furthermore, Crompton, cited in Ross (1998:22), explains that there are 7 push factors which escape from a perceived mundane environment, exploration and evaluation of self, relaxation, prestige, regression, enhancement of kinship relationships and facilitation of social interaction, and 2 pull factors which are novelty and education. 
Singh (2004: 6) states that the expectation level of potential tourists acts as a deciding factor in their decision to visit a certain destination, and the satisfaction level speaks the quality of the composition of tourist product, such as attraction, services, socio-cultural status, economics, ecological environment experienced. Moreover, the expectation level of tourist is the cumulative expression of the degree of their awareness level with regard to the given destination regarding their socio, cultural, or economic background (Lather, 2012: 6).

\section{Research Methodology}

The conceptual study of this research consists of tourist expectation attributes to understand the level of expectation in Ramayana Ballet Prambanan. The expectation level of Ramayana Ballet is collected using a questionnaire developed by the author with 50 respondents. Adapting from the earlier studies by Oliver cited in Singh (2015) with six attributes of expectation namely Information, Aesthetic Appeal, Facilities, Safety and Security, Food, and Acommodation have been measured in the present study and suited with the object of research. The author adapts five from six elements which are Information, Aesthetic Appeal, Facilities, Safety and Security, and Food. In addition, the author also adds several variables adapted by earlier studies (Holden, 2016., Aksu et al, 2010., Zhou, 2015., Bolt, 2014.) suited by the condition of the author object such as Performance, Site Staff Assistance, Accessibility, Weather, and Cleanliness variable.

In addition, push and pull motivation factors may be different from one tourist to another. Therefore, the author does not make any limitation of answer. However, the similar answer will be categorized as one factor. This study conducted using interview with 65 respondents and questionnaire with 100 respondents. The respondents between interview and questionnaire are different due to diversity reason. To be truly representative of the population, a sample must be as diverse as the population itself. Interview method is needed for obtaining information related to tourists motivation factor because the reason behind their coming must be different with others so that the data should obtain very personally without limitation. The data analysis will be explained using descriptive analysis. In order to simplify following discussion, Ramayana Ballet Performance at Prambanan Temple will be referred as RBP.

Data analysis that is used in this research is statistic descriptive analysis method. Descriptive analyses are performed when the study objective is involved in enhancing the reader's knowledge, comprehension and application related to the research (Hussain, 2012: 741). After the data are collected by using questionnaire and supported by interviewing with several respondents, the data will be processed then described into information (Kusmayadi dan Sugiharto, 2000: 178-179). The steps of data analysis in this research will be explained as follows editing, coding, tabulation, and analysis to desctiptive.

\section{Research findings}

\subsection{Push Motivation Factor}

Table 2. Push Motivation Factor of International Tourists Visiting RBP

\begin{tabular}{|l|c|c|}
\hline \multicolumn{1}{|c|}{ Push Motivation Factor } & \multicolumn{2}{|c|}{$\begin{array}{c}\text { Response } \\
\text { (in \%) }\end{array}$} \\
\cline { 2 - 3 } & Yes & No \\
\hline $\begin{array}{l}\text { Ramayana become the main reason for } \\
\text { visiting Yogyakarta }\end{array}$ & 23.1 & 76.9 \\
\hline Easiness to get information about RBP & 81.5 & 18.5 \\
\hline Escape from routine & 86.2 & 13.8 \\
\hline New experience & 92.3 & 7.7 \\
\hline Prestige & 46.2 & 53.8 \\
\hline $\begin{array}{l}\text { RBP the only one night tourism } \\
\text { attraction in Yogyakarta }\end{array}$ & 21.5 & 78.5 \\
\hline
\end{tabular}

Table 2 describes the percentage of international tourists towards their reason behind visiting Ramayana Ballet Prambanan. Author adapts some push motivation factors by Crompton cited in cited in Ross (1998:22) then develop in to interview questions, and suited with the condition in Ramayana Ballet, such as similar dance performance watched, is Ramayana become the main reason for visiting Yogyakarta, easiness to get information about RBP, escape from routine, new experience, prestige, and 
is RBP the only one night tourism attraction in Yogyakarta.

This study reveals that $23.1 \%$ of respondents said that RBP is the main reason for them to come to Yogyakarta. RBP is included in the package tour that they had chosen before they visit Yogyakarta. In contrast, $76.9 \%$ of respondents do not come to Yogyakarta with RBP as the main reason. Based on the interview, several main objects which become the reasons for them to come to Yogyakarta are Borobudur Temple, Prambanan Temple, and Keraton Palace. Some respondents said that RBP is not included to their tour package. Their tour package usually includes Prambanan Temple. However, RBP is excluded. Therefore, they have to pay additional payment as the ticket of RBP.

In addition, about $81.5 \%$ easily find out the information about RBP. Respondents get information from web, tour guide, billboard, and brochure provided in their hotel. On the contrary, a small number of respondents at $18.5 \%$ feel that it is difficult to get information about RBP. They even obtain information after they visited Prambanan Temple and was offered information by officers in Prambanan Temple. Next, there are $86.2 \%$ of respondents come to see RBP based on their ownwill, to escape from routine. Nevertheless, $13.8 \%$ of them see RBP because it is included in the package they bought.

It is only $7.7 \%$ of respondents who are being loyal guests. Reasons why respondents come back to see RBP are because they were satisfied after their first visit, they come back to bring their family, and are still curious with the performance. Meanwhile, some other guests revisit it because they saw Ramayana in outdoor theatre and they come back to see RBP in indoor theatre. On the contrary, $92.3 \%$ of respondents said that they have never seen RBP before either because they have never been to Indonesia or they have ever been to Indonesia but have not seen it yet. Tourism consumer experience comes to life simultaneously with the intention to travel in the form of anticipated experiences, which later influence the perception of the experience. After leaving the destination, the experience is not yet over, and lives on in the form of souvenirs, photos, and acquired habits and activities (Zátori: 12). Seeing this phenomenon, this becomes a challenge for management to always develop the performance into a better quality since most of respondents experience something new when they come to see RBP Prambanan. Their fulfilled expectation makes them as loyal guests.

Dann (1977) was one of the earliest people who focus on prestige as the reason of travelling. $\mathrm{He}$ argued that the desire to be recognized drives humans to look for "ego-enhancement" activities and behavior. After that, Crompton (1979) also identified prestige as a primary motivating factor. However, there is no influence about prestige for some respondents; it can be seen by $53.8 \%$ of them who consider that seeing RBP is not a prestige. On the other hand, $46.2 \%$ of respondents said that see RBP is a pride for them. They could share their experience to their social media, such as Facebook, Twitter, and Instagram, to tell people in their country if they come and see RBP. Prestige motivations depend more on the manner of traveling than on the place visited (Riley 1995). Later, Veblen (1899) considered prestige as a synonym of social standing or honor some groups may possess; then these were a minority in the society.

In addition, there is only $21.5 \%$ of respondents said that they come and see RBP because there is no other night tourism attraction that can be enjoyed but RBP. Otherwise, $78.5 \%$ of them said that there are several night tourism attractions besides RBP. However, they are interested to see RBP. This phenomenon means that majority of respondents know that RBP is not the only night tourism attraction. But still, they choose RBP as their destination. It is shown that respondents have already had information about RBP before.

\subsection{Pull Motivation Factor}

Table 3 shows the amount of percentage of what factors make international tourist attracted to come to RBP. There are 12 factors measured in order to analyze pull motivation factors of international tourists such as Prambanan Temple as the background of the performance, history, the illustration of RBP in Prambanan Temple, Gamelan music instrument, costume, colossal classic dance, dinner package, plot of RBP, Javanese culture representation, lighting, style of the dance, and values contained in RBP.

This study was conducted in January, which was the month of rainy season. The performance 
was mostly presented in indoor theatre and visitors could not enjoy the beautiful Prambanan as the background stage. Based on the result, $67.7 \%$ of respondents said that they want to see RBP with Prambanan as the background. Visitors realized that they could not watch RBP at Open Air Theatre during the rainy season. In addition, respondents with half amount of percentage are not influenced with the background because they are more interested in the dance. The other respondents come to see RBP as the indoor performance. Based on interview, most respondents did not know that there is an alternative place provided to admire Prambanan Temple in the night. It is necessary to provide information that visitors could do such activity from restaurant and there is a new photo spot in indoor theatre area.

Table 3. Push Motivation Factor of International Tourists Visiting RBP

\begin{tabular}{|l|c|c|}
\hline \multirow{2}{*}{\multicolumn{1}{|c|}{ Pull Motivation Factor }} & \multicolumn{2}{c|}{$\begin{array}{c}\text { Response } \\
\text { (in \%) }\end{array}$} \\
\cline { 2 - 3 } & Yes & No \\
\hline $\begin{array}{l}\text { Prambanan Temple as the background } \\
\text { of the performance }\end{array}$ & 32.2 & 67.7 \\
\hline History & 84.6 & 15.4 \\
\hline $\begin{array}{l}\text { The illustration of RBP in Prambanan } \\
\text { Temple, }\end{array}$ & 61.5 & 38.5 \\
\hline Gamelan music instrument & 80.0 & 20.0 \\
\hline Costume & 83.1 & 16.9 \\
\hline Colossal classic dance & 78.5 & 21.5 \\
\hline Dinner package & 67.7 & 32.3 \\
\hline Plot of RBP & 72.3 & 27.7 \\
\hline Javanese culture representation & 89.2 & 10.8 \\
\hline Lighting & 69.2 & 30.8 \\
\hline Style of the dance & 83.1 & 16.9 \\
\hline Values contained in RBP & 75.4 & 24.6 \\
\hline & & \\
\hline
\end{tabular}

Majority of respondents pointed out $84.6 \%$ assumed that the history of Ramayana becomes a pull factor to see the performance. Even some of them specifically learn about Ramayana and compare that history from their country, India. On the other hand, $15.4 \%$ of respondents do not care about the history of Ramayana because they just want to get entertained while staying in Yogyakarta. This high percentage indicates that Ramayana itself has already interesting and widely known. Ramayana story has been developed into several versions around the world. RBP takes version sculpted on Prambanan temple. Due to such varieties, the $\mathrm{MC}$ has to tell more detail of story in order to make visitors understand. Historical side is important to be appeared more, since most of respondents think history is such a big pull factor. A good strategy which has been done by the management is displaying photo of RBP history illustrated in Prambanan Temple relief, in VIP area in Open Air Theatre. Unfortunately, the display is only located in one area.

In addition, there is a big difference among people who are interested in the relief illustrated in Prambanan temple. There are $61.5 \%$ of respondents who are interested in coming to RBP because they are curious after being told about the story illustrated in the relief of Prambanan Temple, especially for the respondents who used tour guide service when they visit Prambanan Temple. Meanwhile, 38.5\% of respondents see RBP not because the relief is illustrated. Meanwhile, they already know the story before, or even they do not know at all if the story of Ramayana is illustrated in relief or Prambanan Temple. The presence of tour guide highly influences Prambanan visitors to also visit RBP. Besides giving explanation, guide could also offer and assist visitors to visit RBP as well. At Open Air theatre in VIP area, there are displays of reliefs on Prambanan Temple. Since the displays are on VIP area, most visitors do not know about this. It is suggested that management should provide some displays of relief related to RBP. Therefore, visitors could get some information before the show.

Furthermore, $80 \%$ respondents who assume that music instruments are factors that cannot be separated from RBP. Collaboration between dance and music is very suitable and make the performance beautiful. Furthermore, there are some respondents who are more interested in Gamelan than the dance. Meanwhile, there are only $20 \%$ of respondents, who are not influenced by Gamelan music instrument because they more focus to the dance.

There are $83.1 \%$ of respondents think that costumes become one of pull factors in the performance. Respondents are interested in costumes which represent Javanese culture. They assume that the costumes are suitable with the character 
of Ramayana. Some respondents are surprised that Ramayana is held in Bali and in Yogyakarta because both type of dance and the costumes they have are different. Next, there are $16.9 \%$ respondents said that there is no influence between the costumes and the dance. Seeing this quite different amount of percentage, RBP management should maintain the costume used by dancers.

One of the uniqueness of RBP is it is danced colossally with 16-20 Gamelan players and 40 dancers in indoor performance, and 100-150 dancers for outdoor performance that make RBP looks more majestic and interesting. There are $78.5 \%$ of respondents agree that $\mathrm{RBP}$ is interesting because it is danced colossally and there are $21.5 \%$ of respondents who are not affected by the number of dancers.

Meanwhile, based on the calculation, $67.7 \%$ of respondents said that besides RBP, the dinner becomes an interesting experience. There are 32.3\% of respondents who are not affected by dinner facility with some reasons. Most reasons are that they already have dinner in the other place, they do not know about the dinner package in RBP, they thought that the price is high because it is not included in their package tour, they do not have enough time for dinner because they come exactly on time with the performance schedule, and they are allowed to take photos with Prambanan Temple as the background, either the visitors who have dinner or not, both can take photos there. Many visitors do not know about dinner program and and the tour package has not included dinner. This fact becomes a challenge for the management to develop a tour package that includes RBP and dinner as well.

There are $27.7 \%$ of respondents who are not interested with the plot of Ramayana. Some respondents do not understand because they do not have imagination of the story and they never know the story before. Therefore, they are confused with the plot of the story although there is a screen provided that explains the story. Meanwhile, $72.3 \%$ of respondents are interested in the story of Ramayana because they have already known the plot, get information from tour guide before the performance, and read synopsis provided by management. This becomes another challenge for management to publish the plot in social media besides photo and video. This could make visitors well educated and ready before they watch the performance. In addition, it is important for the narrator to put in the plot during his prolog.

Based on the interview which reached out $89.2 \%$, it is stated that RBP represents Javanese culture strongly through costume, music instruments, Sinden, etc. Some respondents deplore the unique Javanese costumes are rarely seen in tourism attractions in Yogyakarta. When they come to tourism attractions, employees do not wear Javanese costume and citizen also wear modern clothes so that Javanese culture is less experienced. In contrast, $10.8 \%$ of respondents said that RBP does not represent Javanese culture because they do not know what Javanese culture looks like.

In addition, $69.2 \%$ of respondents agree that lighting becomes an important factor in the performance because the color changes of lighting can describe the differences of location, such as forest dominated by green color, sky dominated by blue color, and angry scenes with fast flashing light red color. On the other hand, $30.8 \%$ of respondents are not affected because the lighting variation is not enough to describe the scene happened.

There are $83.2 \%$ of respondents who assume that the dance style of RBP Prambanan is interesting. They amazed with the agility of Hanoman and deer characters, tenderness of Shinta and Rama, and the dance movement which is difficult to be simulated by respondents. While $16.9 \%$ of respondents are less attracted because they consider that the dance style is just ordinary and the dancers are less cohesive sometimes. This huge differences show that dance style become a pull factor for majority of respondents. Dance style is one of crucial variable to be noticed by management, since the main product of RBP is the dance itself.

Last, $81.5 \%$ of respondents think that values contained in RBP are interesting. The dance illustrates wife's loyalty towards her husband, family orientation, sister's loyalty towards her brother, and Rama Shinta's struggle to find happiness. Meanwhile, $18 \%$ of respondents do not care about the value contained in RBP because they just want to get entertained while they visit Yogyakarta. Seeing this phenomenon, RBP is considered not only give entertainment purpose, but also education purpose since respondents are not originally from Indonesia. They get something to 
be learned about values and norms through dance.

\subsection{Expectation of International Tourist}

In any quantitative measurement of research, validity and reliability test are important, especially in the measurement of covert matters such as the social and psychological constructs that measured things cannot be directly observed sensuously. Due to this reason, it needs the concept of validity and reliability in each measurement. Validity is used as the development and evaluation of a test.

In general, expectation can be defined as performance of establishment, ideal performance or desired performance (Teas, 1994: 134). Due to the effects on tourists' destination selections, consuming of goods and services and having the decision to revisit, expectations of tourists are important to understand to create a successful destination marketing (Stevens, 1992: 46). Moreover, managing tourist expectation is very important as it influences their destination choice and also the perception of experiences (Gnoth, 1997: 283). By understanding tourist's expectations, important clues for developing a destination attractiveness and services will be stated.

\subsubsection{Reliability Test}

Reliability addresses the overall consistency of a research study's measure. If a research instrument, for example a survey or questionnaire, produces similar results under consistently applied conditions, it lessens the chance that the obtained scores are due to randomly occurring factors, like seasonality or current events, and measurement error. Measurement error can be reduced by standardizing the administration of the study, i.e. ensuring that all measurements be taken in the same manner among all the study participants; making certain the participants understand the purpose of the study and the instructions; and thoroughly training data collectors in the measurement strategy (Marczyk et al., 2005). Manfredo, Driver and Tarrant (1996) stated that reasearch is suggested use cronbach's alpha for testing the realibity of the data. Therefore, this study is equipped with a reliability test. Stages of reliability test were used to measure the extent to which the results of a measurement can be trusted. The measurement results were repeated to produce relatively similar results, the measurement is considered to have a good level of reliability. Cronbach's alpha is commonly used as a reliability test:

1. Cronbach's alpha 0,8-1,0: Good

2. Cronbach's alpha 0,6-0,79: Acceptable

3. Cronbach's alpha $<0,6$ : Poor

Based on the results of data processing carried out on ten attributes as presented in the table 4.

Table 4. Reliability Test with Alpha Cronbach Method

\begin{tabular}{|c|c|c|c|c|}
\hline Variable & $\begin{array}{c}\text { Amount of } \\
\text { Statement Item }\end{array}$ & Respondent (N) & $\begin{array}{c}\text { Cronbach's } \\
\text { Alpha }\end{array}$ & $\begin{array}{c}\text { Level of } \\
\text { Reliability }\end{array}$ \\
\hline Information & 4 & 100 & 0,755 & Acceptable \\
\hline Aesthetic Appeal & 2 & 100 & 0,726 & Acceptable \\
\hline Facilities & 4 & 100 & 0,620 & Acceptable \\
\hline Safety and Security & 2 & 100 & 0,621 & Acceptable \\
\hline Food & 2 & 100 & 0,625 & Acceptable \\
\hline Performance & 4 & 100 & 0,734 & Acceptable \\
\hline Site Staff Assistance & 2 & 100 & 0,789 & Acceptable \\
\hline Accessibility & 2 & 100 & 0,728 & Acceptable \\
\hline Weather & 2 & 100 & 0,874 & Good \\
\hline Cleanliness & 2 & 100 & 0,728 & Acceptable \\
\hline
\end{tabular}




\subsubsection{Validity Test}

Validity test is used to judge the quality or merit of a study (Gliner \& Morgan, 2000). As a measure of a research instrument or tool, validity is the degree to which it actually measures what it is supposed to measure (Wan, 2002). If it does not measure what we want it to measure then the results cannot be used to answer the research question, which is the main aim of the study. In other words, if the study is repeated in a different place or with different people, these results cannot then be used to generalise any findings. A key factor for ensuring external validity is obtaining a sample that is representative of the population being studied. Validity is a measure that indicates that the variable that investigated by the researcher (Cooper dan Zulganef, 2006). Ghozali (2009) states that the validity test is used to measure whether a questionnaire is valid or not. A questionnaire is said to be valid if the question on the questionnaire is able to reveal something that will be measured by the questionnaire. Author uses Bivariate Pearson Correlation which collerates each item score with a total score; the total score is the sum of all items. The question items are significantly correlated with the total score indicating the items are valid, as formulation $\mathrm{df}$ (degree of freedom $)=$ $\mathrm{n}-2$ with sig $5 \%$. The result is if $r_{\text {arithmetic }}$ (corrected item) $\geq r_{\text {table }}$ then the instrument or question items are valid. $r_{\text {arithmetic }}$ can be calculated by SPSS. Validity test in this research is tested with 100 respondents, so that $(\mathrm{df}=\mathrm{n}-2)$ will be $\mathrm{df}=100-2$ that is $\mathrm{df}=98$. Based on degree of freedom calculation, $\mathrm{df}=98$ with sig $5 \%$ and SPSS calculation, $r_{\text {table }}$ is 0,194 . The table below describes the validity test calculation.

\subsubsection{Agreement Level of Tourist Expectation}

Table 6 represents the mean of each factor measured. Based on the calculation, the mean "1" shows that so respondents mostly strongly disagree with the factors, while the mean " 2 " is "disagree", the mean " 3 " is "neutral", the mean " 4 " is "agree", and the mean " 5 " is "strongly agree". The expectation level of RBP will be collected using a questionnaire developed by the author. It is adopted from earlier studies by Oliver (1980) with six attributes of expectation namely Information, Aesthetic Appeal, Facilities, Safety and Security, Food, and Accommodation. Those attributes suited into the object of this research. Author adapted five from six elements Information, Aesthetic Appeal, Facilities, Safety and Security, and Food. In addition, author also add several attributes suited by the condition of the research object such as Performance, Site Staff Assistance, Accessibility, Weather, and Cleanliness.

Table 6. Tourist Approval Categories Through Indicator Component of International Tourists' Expectation

\begin{tabular}{|c|c|c|}
\hline Variable & Mean & Std. Deviation \\
\hline Aesthetic Appeal & 4.1850 & .67665 \\
\hline Food & 3.2800 & 1.23975 \\
\hline Information & 4.0475 & .63831 \\
\hline Safety and Security & 3.4400 & 1.08544 \\
\hline Facilities & 4.0350 & .61136 \\
\hline Performance & 4.1975 & .60124 \\
\hline Site Staff Assistence & 4.1000 & .87039 \\
\hline Weather & 3.3200 & 1.06249 \\
\hline Acessibility & 4.1100 & .86334 \\
\hline Cleanliness & 4.3100 & .72048 \\
\hline
\end{tabular}

These attributes are important to be added to determine if there is an empirically provable level of expectation in performing art especially in RBP. Attributes obtained by survey and observation toward RBP and suited by condition of the research object.

There are two parts of questionnaire. The first part is the expectation level measured by calculating the answer from international tourists that indicates either high or low expectation; the higher expectation they choose, then the higher the scale. The questionnaire will be calculated by Likert-type scale. The second part is scales indicate how high international tourist expectation is before they see the performance.

It is shown that Aesthetic Appeal variable reach the average value of 4.18 . This means that from 100 respondents, majority of them answer "Agree", so it can be concluded that their expectation toward Aesthetic Appeal is high. Expectation for this variable is high because as tourists, respondents do not only focus to the RBP performance, they also want to feel Javanese atmosphere with Prambanan Temple as a background.

Based on the data, the mean of Food variable 
Table 5. Validity Test of International Tourists' Expectation

\begin{tabular}{|c|c|c|c|}
\hline Statement & $r_{\text {arithmetic }}$ & $r_{\text {table }}$ & Validity \\
\hline $\begin{array}{l}\text { I expect to find information center easily and get any information } \\
\text { that I need }\end{array}$ & .425 & 0,194 & Valid \\
\hline I expect the availability of the synopsis to be adequate & .565 & 0,194 & Valid \\
\hline $\begin{array}{l}\text { During the performance, I expect the Master of Ceremonies (MC) } \\
\text { will present clear information related to the story }\end{array}$ & .685 & 0,194 & Valid \\
\hline I expect that emergency procedure is directed or announced & .555 & 0,194 & Valid \\
\hline $\begin{array}{l}\text { I expect to see the beautiful Prambanan Temple as a background } \\
\text { of the stage clearly }\end{array}$ & .591 & 0,194 & Valid \\
\hline Javanese cultural atmosphere is expected to be experienced & .591 & 0,194 & Valid \\
\hline $\begin{array}{l}\text { I expect to have a comfortable seat which no one will obstruct } \\
\text { my view }\end{array}$ & .447 & 0,194 & Valid \\
\hline $\begin{array}{l}\text { I expect to see the colossal classic dance provided with a great } \\
\text { stage as well }\end{array}$ & .370 & 0,194 & Valid \\
\hline $\begin{array}{l}\text { I expect the souvenir shop will provide complete character of } \\
\text { Ramayana Ballet with a Various type of goods }\end{array}$ & .368 & 0,194 & Valid \\
\hline $\begin{array}{l}\text { Supporting facilities such as canteen and toilet are expected to } \\
\text { be provided }\end{array}$ & .468 & 0,194 & Valid \\
\hline I expect security check in Ramayana Ballet to be strict & .458 & 0,194 & Valid \\
\hline I expect the emergency procedures to be in large print & .458 & 0,194 & Valid \\
\hline $\begin{array}{l}\text { I expect to experience for having dinner with Prambanan Temple } \\
\text { as background }\end{array}$ & .457 & 0,194 & Valid \\
\hline Good quality of Javanese cuisine is expected to be served & .457 & 0,194 & Valid \\
\hline $\begin{array}{l}\text { During the performance, I expect to experience the traditional } \\
\text { music instrument used }\end{array}$ & .641 & 0,194 & Valid \\
\hline I expect the dance technique performance will be impressive & .625 & 0,194 & Valid \\
\hline $\begin{array}{l}\text { I expect that the lighting used will show the clear changes of the } \\
\text { plot and also resemble Ramayana character's feeling }\end{array}$ & .498 & 0,194 & Valid \\
\hline $\begin{array}{l}\text { During the performance, I expect the plot of the story will surprise } \\
\text { me }\end{array}$ & .392 & 0,194 & Valid \\
\hline $\begin{array}{l}\text { Availability and attitude of the staff on stage is expected to be } \\
\text { adequate }\end{array}$ & .653 & 0,194 & Valid \\
\hline I expect receive a warm and sincere greeting upon arrival & .653 & 0,194 & Valid \\
\hline Accessibility to the Ramayana Ballet is expected to be good & .577 & 0,194 & Valid \\
\hline I expect public transportations are easily found in ballet area & .577 & 0,194 & Valid \\
\hline Clear weather is expected during the performance & .776 & 0,194 & Valid \\
\hline I expect the performance doesn't depend on the weather & .776 & 0,194 & Valid \\
\hline $\begin{array}{l}\text { I expect to experience the cleanliness of every place in Ramayana } \\
\text { Ballet such as in the seat, stage, restaurant, toilet, and many more }\end{array}$ & .458 & 0,194 & Valid \\
\hline Trash bins are expected to be provided in Ramayana Ballet area & .458 & 0,194 & Valid \\
\hline
\end{tabular}


is 3.28, which means that respondents are neutral toward dinner facility with Prambanan Temple as the background. According to the observation, many international tourists come to RBP few minutes before the performance begins so they do not have enough time to enjoy dinner facility provided. In contrast, some international tourists have dinner in RBP because they come too early and wait for the performance to begin, even some of them come to RBP after visiting Prambanan Temple which make them have plenty of time waiting the performance to start.

The mean of Information variable is 4.04 based on calculation above. This means respondents choose "Agree" that shows their expectation is high. Information is an important factor that respondents want to get. It can be shown by their high expectation toward clear information about information center located, synopsis with variants of language, clear information about the plot of RBP explained by Master of Ceremony (MC), and emergency procedure directed by the staff. In outdoor performance, there is certain counter for information center.

On the other hand, there is no information center provided in indoor performance. Nevertheless, many staffs with Javanese costume stand by to serve tourists who need information. Besides, information from $\mathrm{MC}$ explaining about the plot of performance is not detail. However, management provides giant screen using 2 languages; Indonesian and English. Thus, it makes the tourists easier to understand the plot of RBP. Synopsis is provided inside the theatre and will be distributed before the performance is started.

For Safety and Security variable, the mean reaches out 3.44 means that respondents are neutral toward strict security check. This proves that respondents trust and feel safe in RBP. Besides, they do not feel worried about the threats which might be happened. Security staffs in RBP is inadequance and do not wear security uniform, they just look after the location.

Facilities and services at the destination form the major essence of a destination. The success or failure, popularity or non-popularity of the destination depends on this factor, regardless of the natural beauty of that destination. Hence, it is a major factor which plays a key role in formulation of expectation and leads to tourist satisfaction or dissatisfaction. The calculation shows that Facilities variable shows 4.03 with "Agree" as its most answers. It means that respondents have high expectation to have facilities provided by the management.

According to the interview data, respondents have high expectation towards the existence of coffee shop and toilet. In Trimurti Theatre, there is only a toilet for male and female. While there are 4 toilets located in the right and the left behind the stage in Open Air Theatre.

A performance, in the performing arts, generally comprises an event in which a performer or group of performers present one or more works of art to an audience. Usually the performers participate in rehearsals beforehand. Afterwards audience members often applaud (Brown, 2016). Additionally, important elements of the performance such as music instrument and dance technique will support the success of the performance.

The mean of Performance variable reaches out 4.19 shown that respondents choose "Agree" mostly. It can be concluded that expectation of respondents tends to be high. Dynamic Gamelan music instrument, great dance technique, good lighting, and plot become factors which are expected to be good for respondents. A complete Gamelan set is provided by management to satisfy respondents' expectation. In addition, respondents also expect great dance technique suitable with Ramayana characteristic to be performed.

Furthermore, respondents also have high expectation towards lighting for supporting the performance. Lighting is demanded to be good because it is important for the setting changes of the plot. Other than that, the plot of RBP, that is easy to be understood, is expected by respondents, so that tourists who never know about Ramayana story will understand the story after seeing the performance.

The staff assistance should be emphasized mostly for the front-liner staff as they are first persons whom visitors approach upon arriving at the building. Staffs need to be taught on how to interact with persons with disabilities (PWD) and they also need to be ready and willing to assist visitors who need help anytime during their service, especially during an emergency situation (Goodall et al., 2004; Abdul Rahim and Abd Samad, 2010). 
Availability of staff in RBP area pointed the average of 4.10, which means respondents are agree to the statement. Site staff assistance in performance area tends to be high.

It is a fact that weather/climate and tourism/ recreation are interconnected in diverse ways (Lecha and Shackleford, 1997; Shackleford and Olsson, 1995). In addition, the weather acts as a facilitator that makes tourism activities possible and enjoyable (Gómez Martin , 2005). Weather is the state of atmospheric elements such as temperature, precipitation, wind, sunshine, cloudiness, and visibility, whereas climate may be considered the likelihood of different weather conditions occurring.

In this research, respondents already know that Indonesia is having rainy season. Therefore, expectation towards weather is not too high. The weather variable reaches $3.32 \%$. It indicates that respondents are neutral with the weather condition. They are already understood that RBP performance cannot rely on the weather.

Accessibility in tourism is the way of how easy for the tourist to get to the desired destination. Accessibility is the ease of obtaining or achieving organizational goals such as tourism, tourism (travel agents) Mason (2000:46). This means tourist can easily reach the area where attractions are located. Accessibility has an important role for the development of tourism, and it is intended as the set of services and facilities capable of allowing person with specific needs to enjoy a holiday. For Accessibility variable, the mean reaches out 4.11 . It indicates that the respondents agrees and have high expectation. Accessibility obviously has some important roles for a tourism attraction. Main road access, availability of public transportation, and signage board are significant aspects for a tourism attraction.

Cleanliness may be regarded as contributing to other ideals such as 'health' and 'beauty' (Hoy, 1995:3). Cleanliness considered not only focus to the way management tends to the hygiene, but also to the care management takes to maintain all aspects of environments within control. Based on calculation above, it is shown that Cleanliness variable reached the average value of 4.31 . This means that from 100 respondents, majority of them answer "Agree" so it can be concluded that their expectation toward Cleanliness is high. Based on the observation, management provides cleaning service who is standby in every toilet. Therefore, tourists would feel comfortable being around the performance area. However, the trash bin has not distinguished yet between organic and non-organic.

\subsubsection{Scale of International Tourist Expectation Towards RBP}

Table 7. Scale of International Tourist Expectation Towards RBP

\begin{tabular}{|c|c|c|}
\hline Scale & Frequency & Percent \\
\hline 5.00 & 2 & 2.0 \\
\hline 6.00 & 9 & 9.0 \\
\hline 7.00 & 16 & 16.0 \\
\hline 8.00 & 41 & 41.0 \\
\hline 9.00 & 18 & 18.0 \\
\hline 10.00 & 14 & 14.0 \\
\hline Total & $\mathbf{1 0 0}$ & $\mathbf{1 0 0 . 0}$ \\
\hline
\end{tabular}

Table 7 describes the percentage of international tourist of their level of expectation towards RBP performance. Respondents were directed to indicate themselves on how high their expectation about RBP before the performance. The scale of $1-10$ $(1=$ lowest $; 10=$ highest $)$ is provided in this section, in which the bigger number respondents choose indicates the higher expectation they have towards the performance.

International tourists' expectation of RBP tends to be high. It can be shown by the table that scale of expectation reached out minimum at scale of 5 . Other than that, $41 \%$ from 100 respondents indicate their expectation at scale of 8 . Since majority respondents stated that watch RBP is new experience, their expectation about the performance is relatively high.

\section{Conclusion}

This research indicates the biggest factor of international tourists visit Ramayana Ballet Prambanan is new experience. This factor followed by escape from routine, and the easiness to get information about Ramayana Ballet Prambanan.

In addition, the highest pull motivation factor is the attractiveness of Javanese culture. Next, history has become the second main pull 
motivation factor, then followed by the dance and costume. Furthermore, according to the calculation, cleanliness is the highest expected factor for international tourists. Afterward, performance is in second rank of expectation attributes, and followed by aesthetic appeal factor.

Overall, the expectation level of international tourists toward Ramayana Ballet Prambanan is 8 out of 10 . This means that their expectation is tend to be high. Loyal guests tend to choose lower scale than the new guest in RBP. It means novelty affects the level of expectation, and indicates there is a correlation between motivation and expectation.

\section{References}

Aksu, Akin., et al., (2010). “A Comparison of Tourist Expectations and Satisfaction: A Case Study from Antalya Region of Turkey". TURIZAM Volume 14, Issue 2 66-77 (2010)

Chan, J. \& Baum, T. (2007). "Motivation Factors of Ecotourists in Ecolodge Accommodation: The Push and Pull Factors", Asia Pacific Journal of Tourism Research 12:4, 349-364

Dann, M. S. (1977). “Anomie, Ego-Enhancement and Tourism”, Annals of Tourism Research IV(4): 184-194.

Gliner, J.A. \& Morgan, G.A. (2000). Research Methods in Applied Settings: AnIntegrated Approach to Design and Analysis. Mahwah, NJ: Lawrence Erlbaum Associates, Inc.

Gnoth, J. (1997). Tourism Motivation and Expectation Formation. Annals of Tourism Research, 24(2), 283-304.

Hills, J. M. M. 1965 The Holiday: A Study of Social and Psychological Aspects with Special Reference to Ireland. London: The Tavistock Institute of Human Relations

Hughes, Howard L. (1996). "Redefining Cultural Tourism", Annals of Tourism Research 23 (3), 707

Hsu, C.H.C., Cai, L.A., Li, M. (2010). "Expectation, Motivation, and Attitude: A Tourist Behavioral Model". Journal of Travel Research, 49(3), 282

Lather, A. S., R. Singh, K. A. Singh, "Comparing the levels of expectation and satisfaction of Indian and foreign adventure tourists visiting India", Applied Studies in Agribusiness and Commerce - APSTRACT, Agroinform Publishing House, Budapest, vol. 6, no. 3-4, pp. 5-14, 2012.

Lee, S., Jeon, S. and Kim, D. (2011). "The Impact of Tour Quality and Tourist Satisfaction on Tourist
Loyalty: The Case of Chinese Tourists in Korea". Tourism Management, 32(5), 1115

Manfredo, Michael J., et al. (1996). "Measuring Leisure Motivation: A Meta-Analysis of the Recreation Experience Preference Scales”. Journal of Leisure Research, 1996, Vol. 28, No. 3, pp. 188-213

Marczyk, G., Dematteo, D. \& Festinger, D. (2005). Essentials of Research Design and Methodology. Hoboken, NJ: John Wiley \& Sons, Inc.

Ross, Glenn F. (1998). The Psychology of Tourism, Melbourne: Hospitality Press

Singh, R. (2004): Satisfaction level of Foreign Tourist Visiting India, Mohit Publications, New Delhi

Stevens, Blair, F. (1992). Price Value Perceptions of Travellers. Journal of Travel Research 31 (Fall), 44-48.

Teas, R.K. (1994). Expectations as a Comparison Standard in Measuring Service Quality: An Assessment of a Reassessment, Journal of Marketing 58 (1), 132-139.

Yoon, Y. \& Uysal, M. (2005). “An Examination of The Effects of Motivation and Satisfaction on Destination Loyalty: A Structural Model". Tourism Management, 26(1), 45-56.

Yuan, S., \& McDonald, C. (1990). "Motivational Determinates of International Pleasure Travel", Journal of Travel Research, 29(1), 42-44

Zátori, Anita. (2013). Tourism Experience Creation from a Business Perspective. Budapest: Corvinus University NIVERSITY of Budapest 